\title{
The role of serum cystatin $C$ as an early predictor for the diagnosis of chronic kidney disease in Mosul City
}

\author{
*Mohammed Khalid J. Al-Nori,** Akram J. Ahmed \\ *Department of clinical laboratory sciences, College of Pharmacy, University of Mosul. **Department of \\ Biochemistry, College of Medicine, University of Mosul. Correspondence: alnorimikj@yahoo.com

$\frac{\text { Received }}{10.2 .2014} \quad \frac{\text { Accepted }}{13.3 .2014}$

\begin{abstract}
Background: Diagnostic marker to detect chronic kidney disease (CKD) at early stages is important as early intervention can slow the loss of kidney functions. Serum cystatin C ( $\mathrm{sCysC}$ ) is said to be a superior marker for $\mathrm{CKD}$ compared to serum creatinine $(\mathrm{sCr})$ and other known markers in the near past period to detect the mild GFR reduction between 60 and $90 \mathrm{ml} / \mathrm{min} / 1.73 \mathrm{~m}^{2}$.
\end{abstract}

Objective: To detect for detecting the role of cystatin $\mathrm{C}$ as an early predictor for the assessment of chronic kidney disease patients.

Methods: Blood and urine samples from 185 patients suffering from various stages of CKD or subjects under the risk of CKD were taken from Ibn-Sina teaching hospital during the period from $15^{\text {th }}$ of March 2012 to $10^{\text {th }}$ of sept 2013. Serum Urea (sUr), serum uric acid (sUA), serum creatinine ( $\mathrm{sCr}$ ), serum cystatin $\mathrm{C}$ ( $\mathrm{sCysC}$ ), 24 hour excreted urine protein and 24 hour excreted urine creatinine where analyzed then compared to corrected creatinine clearance for each patient.

Results: The results showed that serum CysC started to change from abnormal border line level at stage 2 to clearly abnormal level at stage three of CKD comparing to other assessments which used $\mathrm{sCr}$, sUr, sUA. The results also indicated that the urinary $24 \mathrm{~h}$ excreted protein was starting to be observed at stage 3 of CKD.

Conclusions: The present study indicated that $\mathrm{SCysC}$ have the potential benefit for early detection of CKD especially in those with high risk before appearance of the symptoms and before occurrence of the complications.

Key Words: Chronic Kidney Disease; creatinine; sCys C; Urinary protein; urea; uric acid.

الخلفية : الدلالة التشخيصية للكشف عن مرض الكلى المزمن في المراحل المبكرة تعتبر مهمة لأنها تحد من فقدان

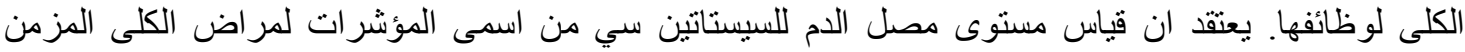
بالمقارنة مع قياس مستوى مصل الدم للكرياتتين و غيرها من المؤشرات المستخدمة مسبقا للكشف عن الاتش الانخفاض

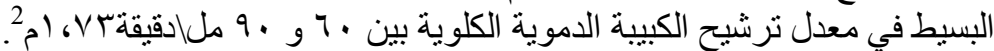

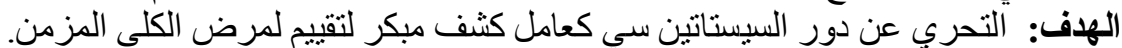

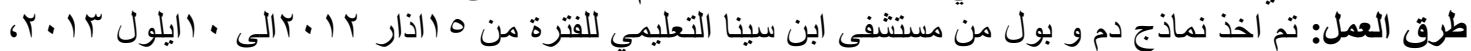

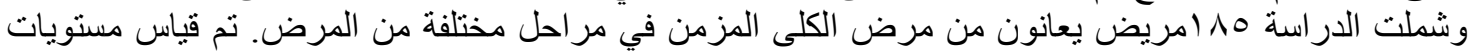

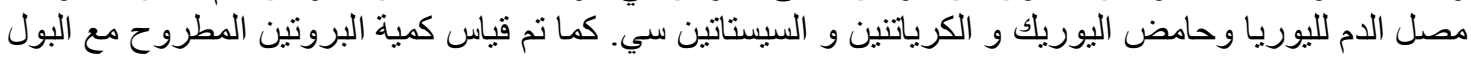

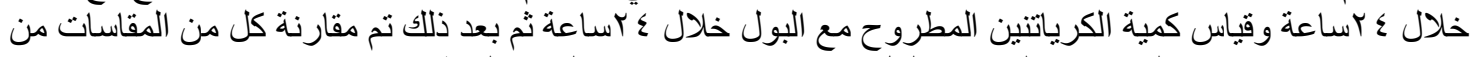

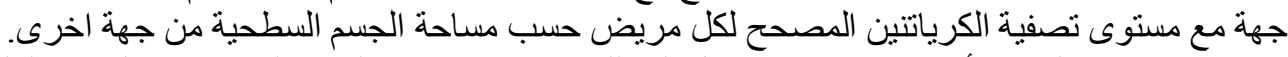

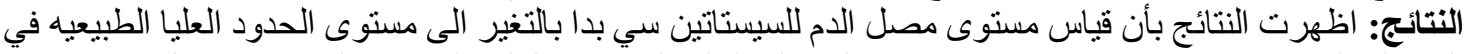
المرحله الثانيه ثم اصبح بمستوى مرضي عند المرحلة الثالثة لمرضى الكلى المزين من بالمقارنة مع كل من قياسات 


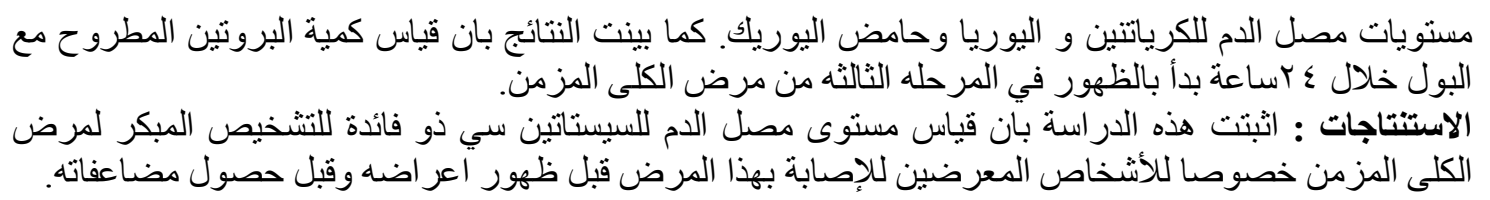

$\mathrm{T}$ he recent considerable interest based on better discrimination for chronic kidney disease (CKD) severity which leads to early recognition of kidney dysfunctions well before changes in $\mathrm{sCr}$ occurred, as it has been evidenced that small or relative increases in $\mathrm{sCr}$ are associated with a concomitant increase in patients mortality even before the increase in $\mathrm{sCr}$ reaches to an abnormal limit $^{1,2}$.

However, even serial evaluation of serum creatinine levels does not allow diagnosing adequately the rapidly evolving changes in renal function in severely ill subjects, therefore, attention has focused on the development of "early" biomarkers, enabling diagnosis of CKD long before creatinine levels start to increase. Logically, a combination of biomarkers could enhance diagnostic accuracy, but validation of current individual candidate biomarker is still underway ${ }^{3,4,5}$.

The limitations of serum creatinine as a measure of glomerular filtration rate (GFR) have led to an extensive search for a more sensitive laboratory marker of impaired kidney filtration function ${ }^{6}$.

Serum cystatin $\mathrm{C}$ level predicts mortality and morbidity more strongly than serum creatinine level in CKD and impaired kidney filtration affections ${ }^{7}$. Cystatin $\mathrm{C}$ is relatively stable, and can be rapidly, accurately, and precisely analyzed by automated analyzers, thereby meeting the practical requirements of a suitable laboratory test $^{8,9}$.
It is well known that serum creatinine is an insensitive measure of renal functions and only loosely corresponding to GFR. Moreover, serum creatinine is not an accurate reflection of GFR in the non-steady state, and is influenced by many factors, including muscle mass, gender, diet, liver functions, and age ${ }^{10}$.

Serum cystatin $\mathrm{C}$ is well known clinically applicable biochemical parameter for assessment of acute kidney failure and it is also now a days start to be an interesting biochemical parameter in assessment of CKD patients (unfortunately not yet for our locality). Furthermore it is useful aid for staging of CKD as it can reflect more rapidly the early changes in kidney functions comparing to the traditional used parameters ${ }^{11}$.

Urea clearance was one of the first clearance tests performed. Urea is freely filtered at the glomerulus and approximately $40 \%$ reabsorbed by the tubules. For this reason, it does not provide a full clearance assessment ${ }^{12}$.

Serum uric acid is commonly elevated in subjects with chronic kidney disease (CKD), but was historically viewed as an issue of limited interest. Recently, uric acid has been reassessed as a potential contributory risk factor in the development and progression of CKD. Most studies documented that an elevated serum uric acid level independently predicts the development of $\mathrm{CKD}^{13}$.

The aim of the current study was to detect the role of serum cystatin $\mathrm{C}$ as an early predictor for the assessment of 
patients with chronic kidney disease in Mosul City.

\section{Subjects, materials and methods}

The patients included in this study were recruited from Ibn-Sina teaching hospital during the period from $15^{\text {th }}$ of March 2012 to $10^{\text {th }}$ of sept 2013. This study included 185 patients suffering from or under the risk of CKD. The studied samples consisted of $124(67 \%)$ males and $61(33 \%)$ females. These studied samples were classified according to the National Kidney Disease Education Program (NKDEP) Classification 14 depending on the corrected creatinine clearance into five stages of CKD.

1. Stage (1), included twenty five subjects under risks of Kidney damage with normal or elevated GFR GFR $>90$ $\mathrm{mL} / \mathrm{min}$ per $1.73 \mathrm{~m} 2$.

2. Stage (2), included forty seven subjects with Kidney damage and mild decrease in GFR GFR of $60-89 \mathrm{~mL} / \mathrm{min}$ per $1.73 \mathrm{~m} 2$.

3. Stage (3), included forty six patients with kidney damage and Moderate decrease in GFR GFR of $30-59$ $\mathrm{mL} / \mathrm{min}$ per $1.73 \mathrm{~m} 2$.

4. Stage (4), included twenty patients with kidney damage and severe decrease in GFR GFR of $16-29 \mathrm{~mL} / \mathrm{min}$ per 1.73 $\mathrm{m} 2$.

5. Stage (5), included forty seven patients with kidney damage and Kidney failure - End Stage Renal Disease (ESRD) GFR of $<15 \mathrm{~mL} / \mathrm{min}$ per 1.73 $\mathrm{m} 2$.

Patients with the following criteria were excluded from the study:

A. Patients with thyroid diseases.

B. Patients with impaired renal function who are receiving corticosteroids.

C. Patients with recent attack of coaggulopathic conditions.

D. Patients on therapies affecting the measured parameters.
E. Pregnant and lactating women.

F. Patients suffered from any type of malignancy.

Venous blood sample (about $10 \mathrm{ml}$ ) was collected from each individual of the studied groups in a plain tube. The tube samples were then placed aside for 15-20 min to enable blood coagulation to occur. The tubes were then centrifuged for $10 \mathrm{~min}$ at $4000 \mathrm{RPM}$ in order to obtain serum samples, separated and collected in aliquots and deep frozen at $20 \mathrm{C}^{\mathrm{o}}$ until analyzed. Urine (24h) samples were also collected. Laboratory tests were achieved on serum and $24 \mathrm{~h}$ urine samples.

Serum urea was measured by enzymatic method ${ }^{15}$, using a kit supplied by Biomerieux company (France). The measurement of serum and urine creatinine were performed using a kit supplied by Randox company (U.K) ${ }^{16}$. Serum uric acid was determined quantitatively by enzymatic colorimetric method utilizing kit supplied by a Randox company (U.K) ${ }^{17}$. Serum cystatin C measurement ST AIA-PACK $\mathrm{Cys} C$ is designed for the quantitative measurement of $\mathrm{sCysC}$ in human serum on TOSOH AIA System Analyzers. ${ }^{18}$. Urine Protein testing by Sulphosalisylic Acid $^{19}$.

\section{Statistical analysis}

The data obtained was analyzed using Statistical Package for Social Sciences (SPSS) program (version 17) ${ }^{20}$.

\section{Results}

The results of this study showed that sCysC started to change for abnormal border line level at stage 2 and became clearly abnormal level at stage $3 \mathrm{CKD}$ (fig. 1) comparing to other assessments which used sCr, sUr, sUA (fig. 2, 3, 4 respectively) which may be more useful 
for early assessment of CKD. The sUA presented with positive relation to progression of CKD stages from 1-4 with mild decrease at stage 5 comparing with previous stage 4 (fig. 4). The results also showed that $24 \mathrm{~h}$ excreted protein (fig. 5) is helpful biochemical parameter for early staging of CKD. In (fig. 6) we can see that despite the decrease of $24 \mathrm{~h}$ urine creatinine excretion through the early stages of CKD which looks logically, in stage 5 there was an increase in the $24 \mathrm{~h}$ creatinine excretion which reflect unexpected result.

The results table shows all parameters in mean \pm SD against the five stages of CKD among the studied subjects.

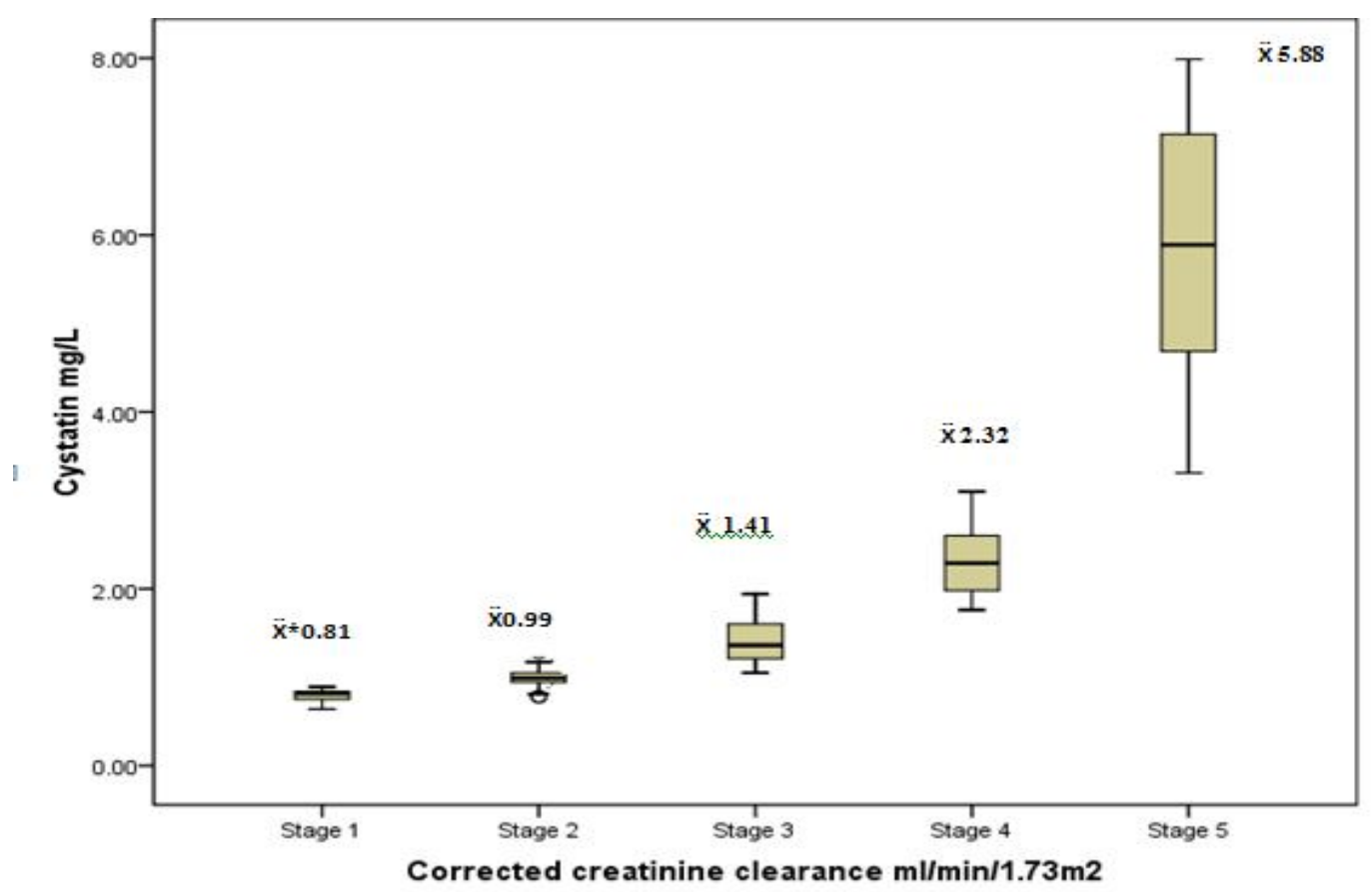

$\ddot{X}=$ mean

Figure 1. showing the change in $\mathrm{sCysC}$ in different stages of $\mathrm{CKD}$ 


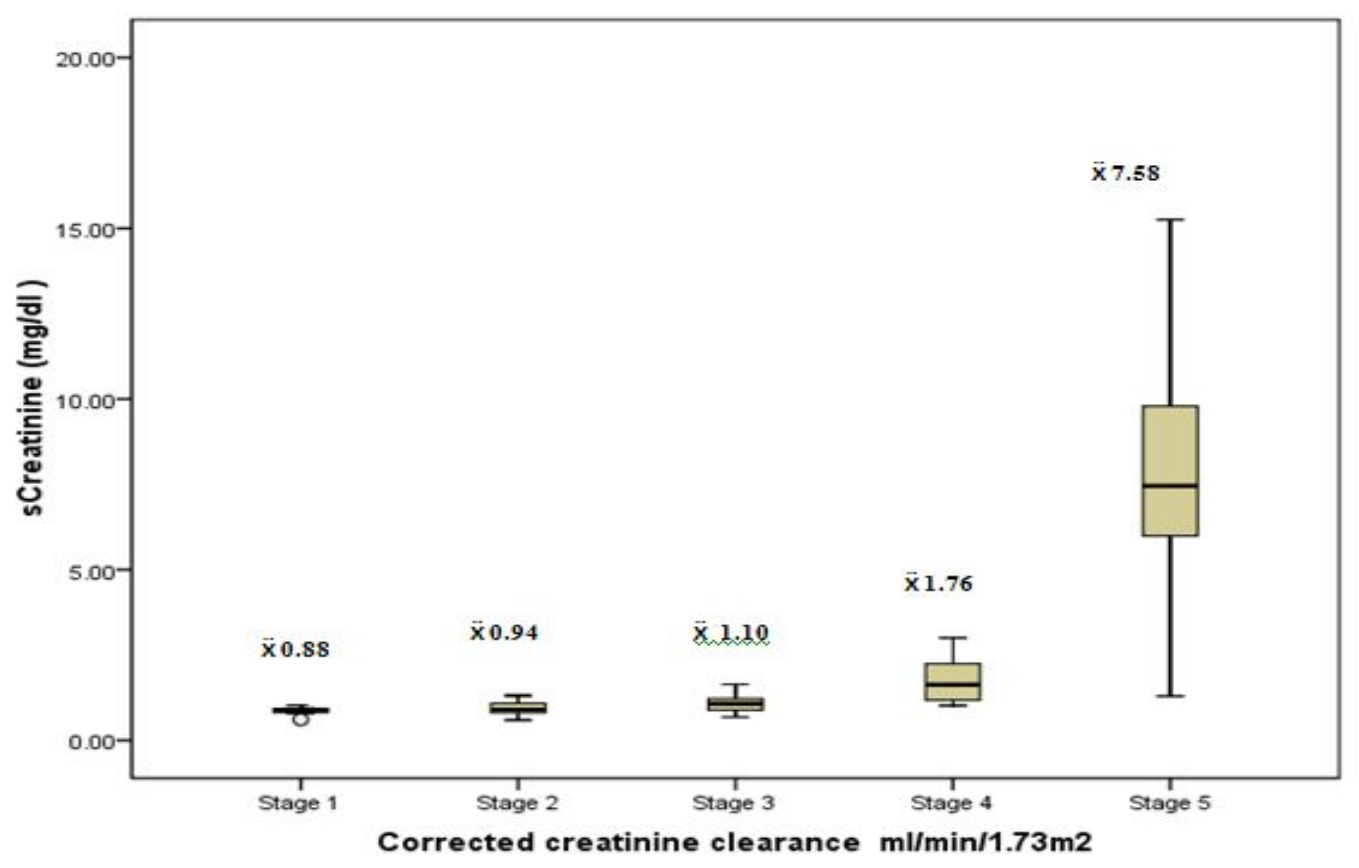

Figure 2. showing the change in $\mathrm{sCr}$ in different stages of $\mathrm{CKD}$

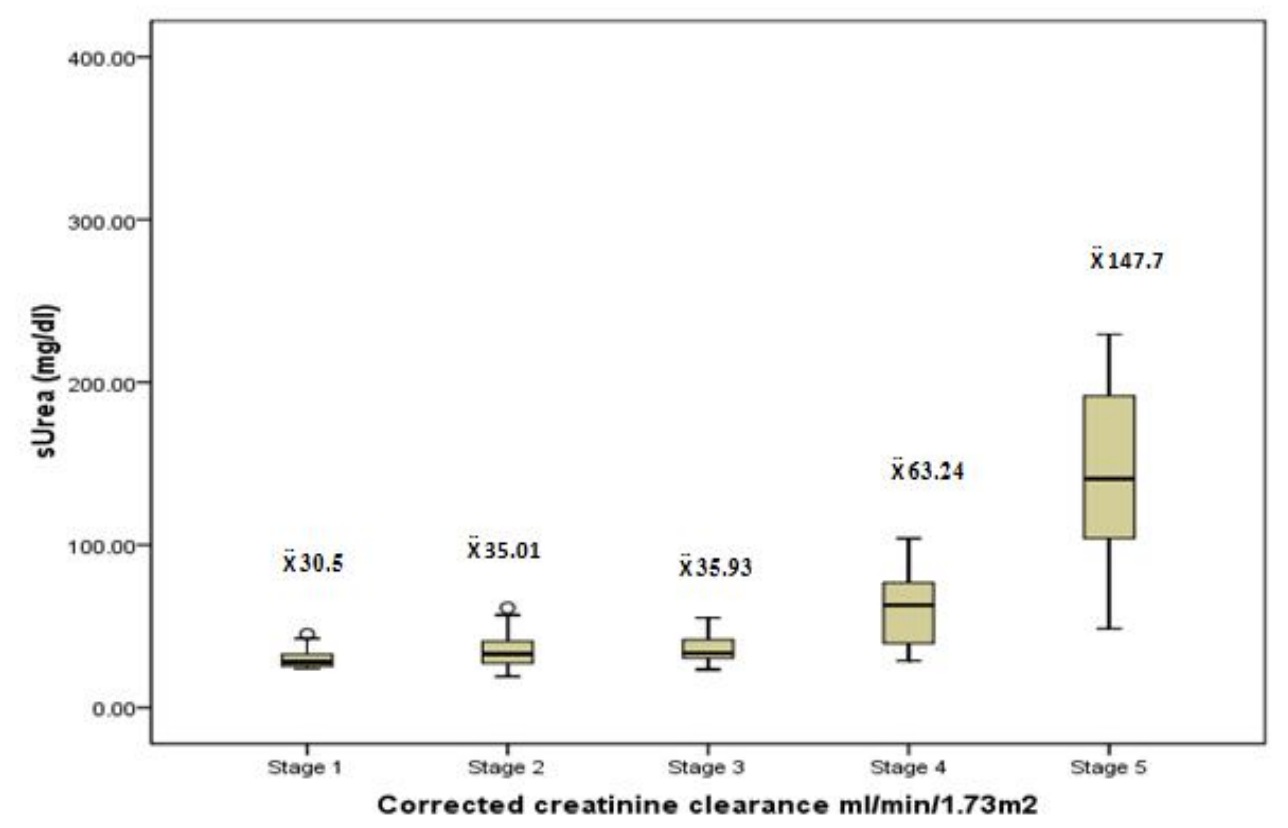

Figure 3. showing the change in sUr in different stages of CKD 


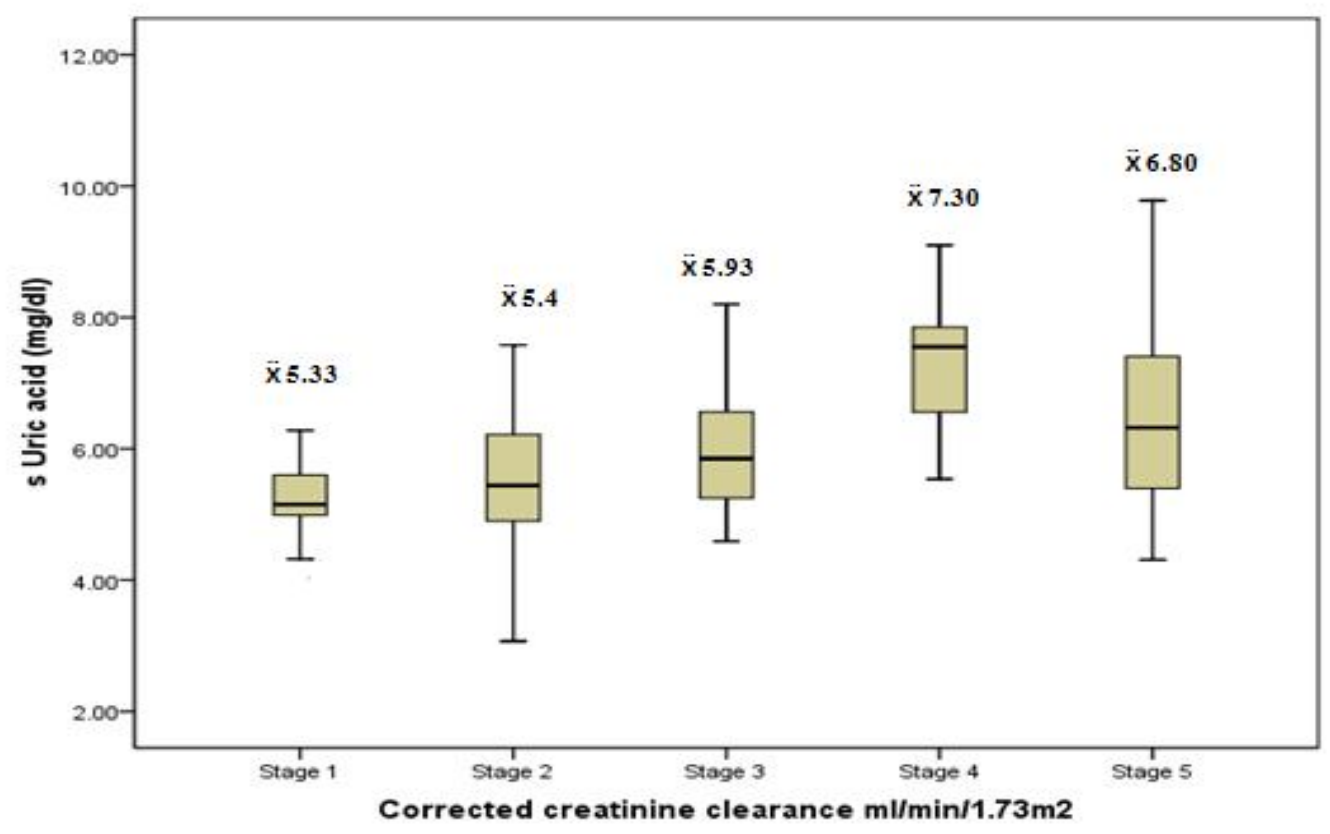

Figure 4. showing the change in sUA in different stages of CKD

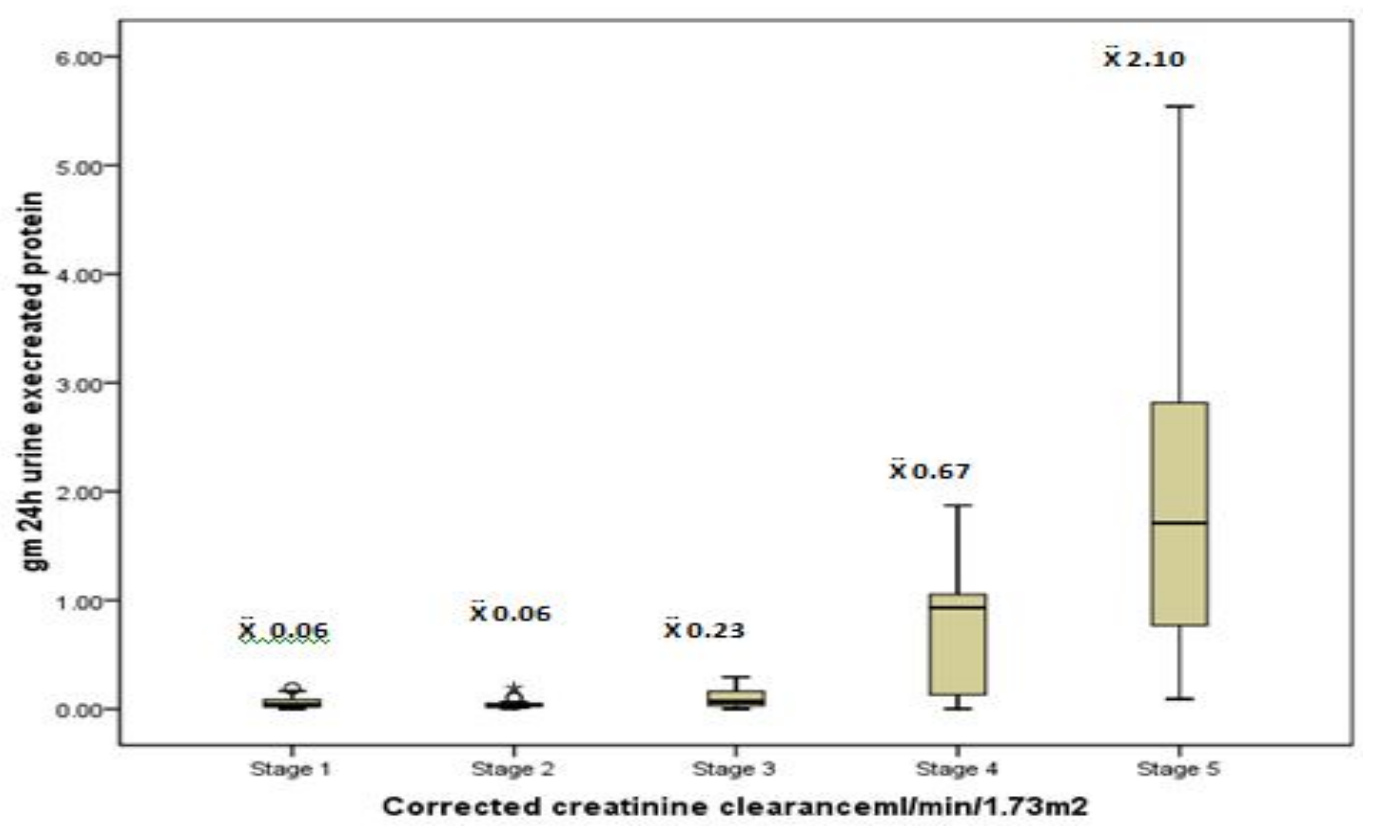

Figure 5. showing the change in urine excreted protein in different stages of CKD 


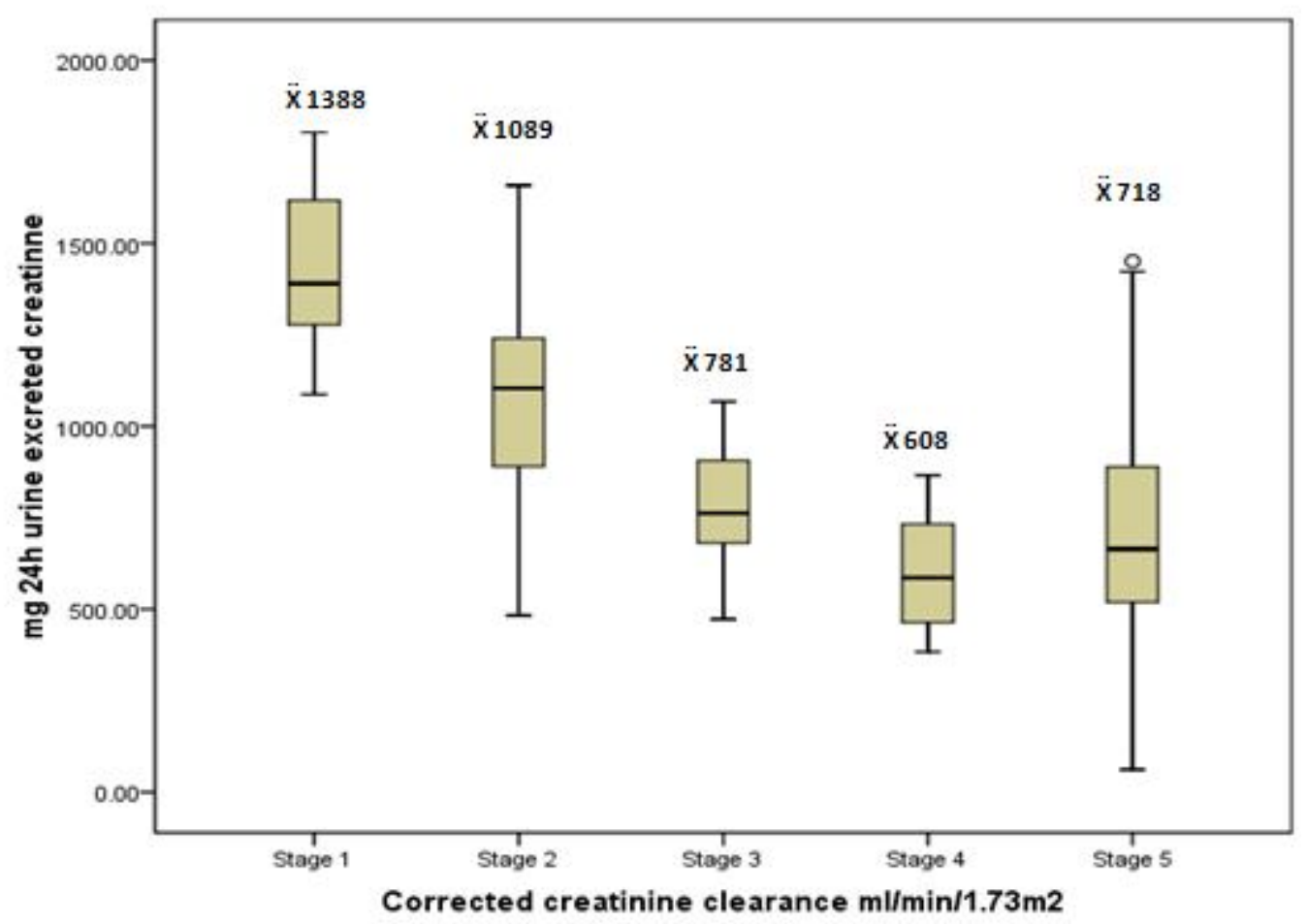

Figure 6. showing the change in urine excreted creatinine in different stages of CKD

Table 1. showing the mean \pm standard deviation of all parameters against the five stages of CKD

\begin{tabular}{|l|l|l|l|l|l|}
\hline parameter & Stage 1 & Stage 2 & Stage 3 & Stage 4 & Stage 5 \\
\hline sCysC mg/L & $0.81 \pm 0.11$ & $0.99 \pm 0.12$ & $1.41 \pm 0.25$ & $2.32 \pm 0.42$ & $5.88 \pm 1.5$ \\
\hline sCr mg/dl & $0.88 \pm 0.11$ & $0.94 \pm 0.20$ & $1.1 \pm 0.27$ & $1.76 \pm 0.64$ & $7.58 \pm 3.58$ \\
\hline sUr mg/dl & $30.5 \pm 6.75$ & $35.01 \pm 10.41$ & $36.93 \pm 7.92$ & $63.24 \pm 22.95$ & $147.7 \pm 67.58$ \\
\hline sUA mg/dl & $5.33 \pm 0.86$ & $5.4 \pm 1.15$ & $5.93 \pm 0.81$ & $7.3 \pm 1.03$ & $6.8 \pm 1.95$ \\
\hline $\begin{array}{l}\text { gm 24 H excreted urine } \\
\text { protein }\end{array}$ & $0.06 \pm 0.06$ & $0.06 \pm 0.09$ & $0.23 \pm 0.52$ & $0.67 \pm 0.6$ & $2.1 \pm 1.61$ \\
\hline $\begin{array}{l}\text { mg 24 H excreted urine } \\
\text { creatinine }\end{array}$ & $1388 \pm 312.8$ & $1089 \pm 307.5$ & $781 \pm 172.2$ & $608 \pm 156.9$ & $718 \pm 344.6$ \\
\hline
\end{tabular}

\section{Discussion:}

Serum cystatin $\mathrm{C}$ has been proposed as an ideal marker for assessing the GFR. A number of studies have shown that ${ }_{\mathrm{sCys}} \mathrm{C}$ is a more sensitive indicator of an early and mild reduction in renal functions than $\mathrm{sCr}^{21,22,23}$.

The results of the current study showed that $\mathrm{sCys} C$ started to change for abnormal border line level at stage 2 and became clearly abnormal level at stage 3 
CKD comparing to other assessments which used sCr, sUr, sUA which may be more useful for early assessment of CKD. This result looks logically correct as $\mathrm{sCys} C$ level is stable and independent of body weight, height, and muscle mass. It is produced at a stable rate, which is unaffected by sex, age, diet, and nutritional status ${ }^{9}$. However, it is relatively recently introduced, there are only limited numbers of studies for sCysC in the Middle East general population.

Serum cystatin $\mathrm{C}$ results agree with a study accomplished in Malaysia which showed that $\mathrm{sCysC}$ increased with the progression $\mathrm{CKD}$, and it was significantly higher in subjects with mild to moderate estimated GFR (eGFR) (stages 2 and 3.), but not significant in stage 1 . This Malaysian study mentioned that $\mathrm{sCysC}$ has been demonstrated to be more accurate than serum creatinine in the detection of early renal impairment and in specific populations may allow for early detection of renal disease ${ }^{24}$. Astor et al 2012 concluded that sCysC had advantage over eGFR CKD in predicting kidney failure and it may be helpful in improving estimation of risk associated with decreased kidney function beyond current estimates based on eGFR CKD(Serum creatinine-based estimated glomerular filtration rate calculated using the CKD Epidemiology Collaboration (CKD-EPI) equation) ${ }^{25}$.

A Study conducted upon multiMulti-Ethnic atherosclerosis affected patients mentioned that sCysC level and microalbuminuria are independent risk factors for incident CKD stage 3 and could be useful as screening tools to identify those at increased risk $^{26}$. Whereas another study by katharina et al. reported that the diagnostic performance of serum creatinine, $\mathrm{sCysC}$, or $\beta$-Trace Protein (BTP) for detecting even minor degrees of deterioration of renal function is very helpful ${ }^{27}$.

However, unfortunately there is evidence that $\mathrm{sCysC}$ level may be changed independent to the renal function in case of inflammation, and like many other markers of inflammation, its plasma concentration may be higher in patients with decreased renal clearance ${ }^{28}$. Peralta et al reported that among adults diagnosed with CKD using the creatinine-based CKD-EPI equation, the adverse prognosis is limited to the subset who also have CKD according to the sCysC-based equation, so $\mathrm{sCysC}$ may have a role in identifying persons with CKD who have the highest risk for complications ${ }^{29}$.

A recent study by Min et al in a meta-analysis demonstrated significant correlations between $\mathrm{sCysC}, \mathrm{SCr}$ and GFR. Cystatin C was more sensitive, but less specific in early diagnosis of CKD, than $\mathrm{SCr}$ for the estimation of GFR ${ }^{30}$. Xun et al concluded that $\mathrm{sCys} \mathrm{C}$ is more sensitive in diagnosis of early stages of renal impairment comparing to other conventional assessments methods ${ }^{31}$. The results of this study also show that $24 \mathrm{~h}$ urinary excreted protein is helpful biochemical parameter for early staging of CKD but unfortunately the obstacles of $24 \mathrm{~h}$ urine collection and possible errors by the patient during that collection limits its usage. Urinary albumin excretions were strongly correlated with the renal endpoint ${ }^{32}$.

On the other hand despite the decrease of $24 \mathrm{~h}$ urine creatinine excretion through the early stages of CKD which looks logically, in the stage 5 there was an increase in the $24 \mathrm{~h}$ creatinine excretion which reflect unexpected result which could be as a result of strict supervision by the 
managing doctors which may affect the potential of the present renal functions. Concerning the use of $24 \mathrm{~h}$ corrected creatinine clearance, it like the assessment of $24 \mathrm{~h}$ urinary protein excretion, the only limitation was that patients could have made errors during the 24-hour urine collection, which will negatively affect the predictive performance of the 24-hour urinary creatinine excretion otherwise it may be considered as the most actual indicator for measuring the early renal nephropathy ${ }^{4}$.

Serum uric acid and serum urea showed significant increase in their concentration in late stage of CKD specially in stage 4 and 5 but not at early stages 1,2 and 3, this may indicate that those two indicator are only good in late stages of CKD prediction with further limitation as those two parameters are non specific and may be increased in different other medical conditions like increased protein food intake, debilitating diseases, in acute systemic infections and malagnancy. This agrees with Diana et al results whom indicated that serum uric acid levels are a strong predictor of micro- or macroalbuminuria in patients with CKD with several limitations ${ }^{33}$.

In another recent study accomplished by Meena et al, the study demonstrated a strong independent association between uric acid level and protein urea without association with decreased renal function $^{34}$ while in large, prospective cohort study of type 1 diabetic patients without proteinuria, Linda et al found that serum uric acid was an important predictor of the development of early GFR loss ${ }^{35}$. Giacomo et al. 2012 conclude that in type 2 diabetic individuals with preserved kidney function, hyper-uricemia seems to be an independent risk factor for the development of incident $\mathrm{CKD}^{36}$. While the present result shows mild decrease in stage $5 \mathrm{CKD}$ comparing to stage 4 for sUA, this could be attributed to protein intake restriction advised by managing doctors.

Conclusions: The present study indicated that $\mathrm{sCysC}$ have the potential benefit for detecting early CKD especially in those with high risk.

\section{References}

1. Groop PH, Thomas MC, Moran JL, et al. The presence and severity of chronic kidney disease predicts all-cause mortality in type 1 diabetes. Diabetes 2009;58:1651-1658.

2. Rule AD, Glassock RJ. GFR estimating equations: Getting closer to the truth? Am Soc Nephrol 2013;10:2215-2218.

3. Zachariah D, Olechowski B, Kalra PR. Clinical utility of biomarkers in chronic kidney disease and chronic heart failure. J Ren Care 2013;39(3):128-139.

4. Fassett R, Venuthurupalli SK, Gobe $\mathrm{CG}$ et al. Biomarkers in chronic kidney disease. Kidney International 2011;80: 806-821.

5- Wang C, CuiCui L, Gong W, et al. New urinary biomarkers for diabetic kidney disease. Biomarker Res 2013;1(9):1-4.

6. Eun-Young L, Young-Mi L, Kyu-Hun C. Comparison of two creatinine-based equations for predicting decline in renal function in type 2 diabetic patients with nephropathy in a Korean population. Inter J Endocr 2013;2013:1-8.

7. Maria AD, Daniel OB, Beata MR, et al. Cystatin $\mathrm{C}$ at admission in the intensive care unit predicts mortality among elderly patients. ISRN Nephrol 2013;2013: 1-6. 
8. Lu W, Xiaoshuang Y, Xiaohua $\mathrm{P}$, et al. Reference intervals for serum cystatin $\mathrm{C}$ and factors influencing cystatin $\mathrm{C}$ levels other than renal function in the elderly. J pone 2014;9(1):1-6.

9. Li J, Dunn W, Breaud A, et al. Analytical performance of 4 automated assays for measurement of cystatin C. Clin Chem 2010;56(8):1336-1339.

10. Neil DR. Serum Creatinine and Glomerular Filtration Rate: Perception and Reality. Clinical Chemistry 2010,56(5):687-689.

11. Fathil E, Mesbah SA, Farahzadi R. Biomarkers in medicine: An overview. B J M 2014;4(8):1701-1718.

12. Nosratola D, Vaziri JY, Nazertehrani S. Chronic kidney disease causes disruption of gastric and small intestinal epithelial tight junction. Am J Nephrol 2013;38:99-103.

13. Johnson RJ, Nakagawa T, Jalal D, et al. Uric acid and chronic kidney disease: which is chasing which? Nephrol Dial Transplant 2013;28(9):2221-2228.

14. Levey AS, Eckardt KU, Tsukamoto Y, et al. Definition and classification of chronic kidney disease: A position statement from Kidney Disease: Improving Global Outcomes (KDIGO). Kidney Int 2005;67:2089-2100.

15. Fawcett JK, Scott JE. A rapid and precise method for the determination of urea. J clin path 1960;13:156-159.

16. Spencer KS. Analytical reviews in clinical biochemistry, the estimation of creatinine. Ann Clin biochem 1986;1:125.

17. Artiss JD, Entwistle WM. The application of sensitive uricaseperoxidase coupled reaction to centrifugal fast analyzer for the determination of uric acid. Clin Chim Acta 1981;116: 301-309.
18. Tosoh Bioscience. Quantitative measurement of cystatin $\mathrm{C}$ in human serum on TOSOH AIA System Analyzers. 2011; www.diagnostics. eu. tosohbioscience.com

19. Henry RJ, Sobel C, and Segalove M. Turbidimetric determination of proteins with sulfosalicylic and trichloroacetic acid. Proc Soc Exp Biol Med 1956; 12:148. (Abstract).

20. Bryman A, Cramer D. Quantitative data analysis with IBM SPSS 17, 18 and 19: a guide for social scientists. Hove; New York: Routledge; 2011.

21. Li F, Lesley A, Jerome $R$, et al. Glomerular filtration rate estimation using cystatin $\mathrm{C}$ alone or combined with creatinine as a confirmatory test. Nephrol Dial Transplant 2014; 10:1093.

22. Kukla A, Issa N, Jackson $\mathrm{S}$, et al. Cystatin $\mathrm{C}$ Enhances glomerular filtration rate estimating equations in kidney transplant recipients. Am J Nephrol 2014; 18; 39(1):59-65.

23. Mattia AE, Hans LH, Gerjan N, et al. The chronic kidney disease epidemiology collaboration equation outperforms the modification of diet in renal disease equation for estimating glomerular filtration rate in chronic systolic heart failure. European Journal of Heart Failure 2014;16(10):86-94.

24. Zati AK, Ruziana WZ, Nor Idayu R, et al. The usefulness of cystatin $\mathrm{C}$ as a marker for chronic kidney disease. Ujcm 2013;1(2):28-33.

25- Astor BC, Shafi $T$, Ron $C$, et al. Novel markers of kidney function as predictors of ESRD, cardiovascular disease, and mortality in the general population. Am J Kidney Dis 2012;59(5):653-662.

26. Shastri C, Ronit K, Michael G, et al. Cystatin $\mathrm{C}$ and albuminuria as risk factors for development of CKD Stage 3. Am J Kidney Dis 2011;57(6):832-840. 
27. Katharina SS, Barbara K, Eberhard $\mathrm{R}$, et al. Serum creatinine, cystatin $\mathrm{C}$, and $\beta$-trace protein in diagnostic staging and predicting progression of primary non diabetic chronic kidney disease. Clin Chem 2010;56(5):740-749.

28. Font RM, Gutiérrez C, Bardají AM, et al. Is there a relationship between cystatin $\mathrm{C}$ and inflammatory status, oxidative stress and other cardiovascular risk factors in non-diabetic patients with chronic kidney disease? Nefrologia 2009;29(3):228-35.

29. Peralta CA, Ronit $K$, Mark JS, et al. Cystatin C identifies chronic kidney disease patients at higher risk for complications. JAm Soc Nephrol 2011;22:147-155.

30. Min Z, Xueying C, Guangyan C, et al. Clinical evaluation of serum cystatin $\mathrm{C}$ and creatinine in patients with chronic kidney disease: A meta-analysis Journal of International Medical Research 2013;56:1-12.

31. Xun C, Peng X, Meizhen G, et al. Measurement of serum cystatin $\mathrm{C}$, creatinine clearance and urea microalbumin as renal function evaluation indicators in cancer patients during chemotherapy with platinum. Chinese-
German journal of clinical oncology 2011;10(4):235-239.

32. Hiddo JH, Ron TG, Barry MB, et al. Comparison of different measures of urinary protein excretion for prediction of renal events. J Am Soc Nephrol 2010;21:1355-1360.

33. Diana IJ, Christopher J, Richard J, et al. Serum uric acid levels predict the development of albuminuria over 6 years in patients with type 1 diabetes: findings from the coronary artery calcification in type 1 diabetes study. Nephrol Dial Transplant 2010;25:1865-1869.

34. Meena CL, Harsa M, Anju B, et al. Association of serum uric acid and microalbuminuria in prehypertension : A cross sectional study. National Journal of Physiology, Pharmacy \& Pharmacology 2013;3(1):87-91.

35. Linda HF, Elizabeth TR, Monika A, et al. High-normal serum uric acid increases risk of early progressive renal function loss in type 1 diabetes. Diabetes Care 2010;33:1337-1343.

36. Giacomo Z, Giovanni $T$, Michel $C$, et al. Serum uric acid levels and incident chronic kidney disease in patients with type 2 diabetes and preserved kidney function. Diabetes Care 2012;35:99-104. 